\title{
Factors Influencing the Extent of Technological Gap in Adoption of Scientific Practices of Tea Cultivation by Small Tea Growers of Assam
}

\author{
S. Parasar ${ }^{1}$, P. K. Das ${ }^{2}$, I. Barman ${ }^{2 *}$, S. Sultana ${ }^{3}$, S. Barman ${ }^{4}$, \\ S.D. Deka ${ }^{5}$, N. Baruah ${ }^{6}$ and R. Islam ${ }^{7}$ \\ ${ }^{1}$ ATM, ATMA, DAO Office, Jorhat, Assam, India \\ ${ }^{2}$ Department of Extension Education, ${ }^{5}$ Department of Agril. Statistics, ${ }^{7}$ Department of Animal \\ Husbandry \& Dairying, Biswanath College of Agriculture, AAU, Assam, India \\ ${ }^{3} A P A R T, A A U$, Jorhat, India \\ ${ }^{4}$ Department of Extension Education, College of Agriculture, AAU, Assam \\ ${ }^{6}$ AICRPDA, AAU, Assam, India \\ *Corresponding author
}

\section{Ke yw o r d s \\ Technological gap, Factor, Small TEA GROWERS (STG), Assam \\ Article Info \\ Accepted: \\ 17 June 2020 \\ Available Online: \\ 10 July 2020}

\section{A B S T R A C T}

The study was conducted in Sonitpur and Biswanath districts of Assam with 100 Small Tea Growers to identify the factors influencing the extent of technological gap in adoption of scientific practices of tea cultivation by small tea growers. An analysis of the small tea production system is the quite important to the subject of development of the small tea growers as well as improving the productivity tea on small holdings. It was found that majority of the respondents $(71.00 \%)$ had medium overall technological gap in adoption of scientific practices of tea cultivation followed by 17.00 per cent respondents with low overall technological gap. The findings also revealed that practice wise maximum average technological gap was found in adoption of Doses of YTD mixture (70.90\%) followed by Size of planting pit and Number of ploughing and harrowing with average technological gap scores being $61.71 \%$ and $57.21 \%$ respectively. The findings of correlation analysis revealed that variables viz. area under tea, management orientation, risk bearing ability, decision making ability, scientific orientation, exposure to training, knowledge level on scientific practices of tea cultivation, family type, economic motivation and working capital availability for tea cultivation had negative and significant relationship with extent of technological gap. So, there is a need for extension agencies and other concerned departments to positively manipulate these crucial factors in order to bridge the technological gap in adoption of scientific practices of tea cultivation by the small tea growers. The variables which were significantly correlated with the extent of technological gap in scientific practices of tea cultivation were further considered for multiple regression where the value of $\mathrm{R}^{2}(0.5466)$ indicated that 10 independent variables could explain $54.66 \%$ of the variation in the extent of technological gap in adoption of scientific practices of tea cultivation by the small tea growers. 


\section{Introduction}

Tea is one of the oldest and well organized industries in India and it plays an important role in the national economy. India is the second largest producer of tea (1116 million $\mathrm{kg}$ ) in the world after China (Arya, 2014). Within the tea producing countries, the small tea growers (STGs) play an important role world-wide. In India, an estimated 160000 small-holders account for over 26 per cent of its production of 1116 million kilograms. Moreover, there has been an enormous growth of small growers as compared to the large-scale organized sector in the past three decades. The advent of a large number of small tea growers in recent years is a significant development in the tea industry and socio-economic sphere of Assam. According to All Assam Small Tea Growers Association (AASTGA), there is 1, 18,832 STGs spread across the state and their cuttivation area is estimated at 2.50 lakh hectares. These small tea growers produced $8820,594,234 \mathrm{~kg}$ green leaf during the year 2014-15. In 2014, STGs provided 170 million $\mathrm{kg}$ made tea, contributing 33.00 per cent to the total production of the state and 28.00 per cent of the area. An analysis of the small tea production system is the quite important to the subject of development of the small tea growers as well as improving the productivity tea on small holdings. Choosing policies for development of STGs requires the use of information about the situation existing in the small tea gardens. Keeping these facts in view, the present study was undertaken to identify the factors influencing the extent of technological gap in adoption of scientific practices of tea cultivation by small tea growers.

\section{Materials and Methods}

A purposive-cum-random sampling technique was followed for selection of 100 respondents

which constituted the sample for the study. The study was conducted in Sonitpur and Biswanath districts selected at random under North Bank Plain Agro Climatic Zone of Assam. Only those small tea growers who had a minimum of 1 ha of land under tea cultivation were considered for inclusion in the sample of the study. The data for the study were collected by the personal interview method with the help of a structured research schedule.

Technological gap for scientific practices of tea was calculated by adopting the procedure followed by Das (2013). The technological gap was calculated for 19 selected scientific practices of tea as recommended by Assam Agricultural University and Tea Research Association, Tocklai Experimental Station, Jorhat, Assam. The data related to adoption gap in a particular practice of tea cultivation was obtained as follows.

Technology Gap in the practice $=$

Deviation from the recommended practice Recommended practice $\quad \times 100$

The scoring for each gap under each practice was done accordingly. Thus, if a respondent has 100 percent gap in a certain practice, his score will be 10 for that practice. Based on

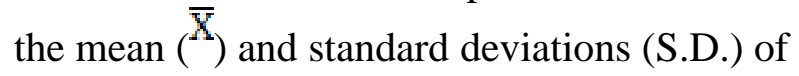
the obtained scores, respondents were classified into three categories as shown below:

Categories

Low technology gap

Medium technology gap High technology gap

\section{Score range}

Upto ( $\overline{\mathrm{X}}-1$. S.D.)

( $\overline{\mathrm{X}}-1$. S.D.) to $(\overline{\mathrm{X}}+1$. S.D. $)$

Above ( $\overline{\mathrm{X}}+1$.S.D.) 
In order to identify the factors influencing the extent of technological gap in adoption of scientific practices of tea cultivation by small tea growers, the relationship of selected independent variables with technological gap in adoption of scientific practices of tea cultivation was examined with the help of zero order correlation coefficient. A total of 19 independent variables viz, age, education, family type, family size, occupational status, institutional linkage, experience as tea grower, area under tea, net annual income from tea cultivation, exposure to training, working capital availability for tea cultivation, utilization of information source, farm mechanization, economic motivation, management orientation, risk bearing ability, scientific orientation, decision making ability and knowledge level on scientific practices of tea cultivation were selected for examining their relationship with extent of technological gap in adoption of scientific practices of tea cultivation. The significance of an observed correlation coefficient was ascertained with the help of ' $t$ ' test. The decision criterion was stipulated at 0.01 and 0.05 level of probability.

\section{Results and Discussion}

Extent of technological gap in adoption of scientific practices of tea cultivation

The distribution of respondents according to their overall technological gap in adoption of scientific practices of tea cultivation is shown in Table 1.

Table 1 reveals that majority of the respondents $(71.00 \%)$ had medium overall technological gap in adoption of scientific practices of tea cultivation followed by 17.00 per cent respondents with low overall technological gap in adoption of scientific practices of tea cultivation. A small percentage of them $(12.00 \%)$ were found with high overall technological gap in adoption of scientific practices of tea cultivation.

The overall mean technological gap score was 41.16 per cent indicating medium extent of overall technological gap in adoption of scientific practices of tea cultivation in the sample of the study.

The value of co-efficient of variation (8.28) indicated that respondents were highly homogenous with respect to their extent of overall technological gap in adoption of scientific practices of tea cultivation.

\section{Practice wise average technological gap in adoption of scientific practices of tea cultivation}

A perusal of the Table 2 reveals that there was substantial extent of technological gap in adoption of scientific practices of tea cultivation by the small tea growers. The maximum average technological gap was found in adoption of Doses of YTD mixture (70.90\%) followed by Size of planting pit and Number of ploughing and harrowing with average technological gap scores being $61.71 \%$ and $57.21 \%$ respectively.

There was substantial extent of technological gap in adoption of scientific practices of tea cultivation like Height of light pruning $(49.70 \%)$, Length of pruning cycle $(48.90 \%)$, Chemical pest control (48.40\%), Mulching practice $(48.11 \%)$, Height of centering $(48.00 \%)$, Interval of irrigation $(43.41 \%)$, Time of light pruning $(41.41 \%)$, Doses of chemical weedicide $(38.80 \%)$, Doses of chemical pesticides $(37.81 \%)$, Procedure of green leaf handling $(37.80 \%)$, Size of main drain (36.10\%), Time of vegetative propagation $(32.60 \%)$, Number of plucking round $(27.00 \%)$, Maintenance of spacing (23.90\%), Planting time (16.61\%) and use of Planting material ( $13.90 \%$ ). 
Factors influencing the extent of technological gap in adoption of scientific practices of tea cultivation

It is evident from Table 3 that 10 independent variables were significantly and negatively correlated with the extent of technological gap in adoption of scientific practices of tea cultivation. While the variables area under tea, management orientation, risk bearing ability, decision making ability, scientific orientation, exposure to training and knowledge level on scientific practices of tea cultivation had significant and negative correlation with the extent of technological gap in adoption of scientific practices of tea cultivation at 0.01 level of probability, the variables family type, economic motivation and working capital availability for tea cultivation showed significant and negative correlation with the extent of technological gap in adoption of scientific practices of tea cultivation at 0.05 level of probability. Hence the corresponding null hypotheses stating that these independent variables have no significant relationship with the technological gap in adoption of scientific practices of tea cultivation by the small tea growers were rejected and alternative hypotheses were tentatively accepted. The findings of the present study are supported by the findings of Shukla (1980), Ahir (1985), Kunzru et al., (1989), Bora (1990), Das (1991), Tharker and Patel (1991), Chutia (1992), Pathok and Sasmal (1992), Koul (1993), Kalavathy and Anithakumari (1998), Vennila and Annamalai (2002) and Gohain (2006) and Kumar et al., (2014).

The variables age, education, family size, information source utilization, institutional linkage, experience as tea grower, occupational status, net farm income, farm mechanization had no significant relationship with the technological gap in adoption of scientific practices of tea cultivation. Hence the corresponding null hypotheses stating that these independent variables have no significant relationship with the technological gap in adoption of scientific practices of tea cultivation by the small tea growers could not be rejected.

The variables which were found to have significant correlation with the technological gap in adoption of scientific practices of tea cultivation were further selected for multiple regression analysis with a view to determining the relative influence of those variables in predicting the variation in the technological gap in adoption of scientific practices of tea cultivation by the small tea growers. The predictive power of multiple regressions was estimated with the help of coefficient of multiple determinations $\left(\mathrm{R}^{2}\right)$. The results of the regression analysis are presented in table 4. A perusal of the Table 4 reveals that out of 10 independent variables, only 4 variables, viz. economic motivation, decision making ability, exposure to training and knowledge level were found to contribute significantly towards the variation in technological gap in adoption of scientific practices of tea cultivation by the small tea growers. The value of $R^{2}(0.5466)$ indicated that 10 independent variables selected for the study were efficient in predicting the extent of technological gap in adoption of scientific practices of tea cultivation. The 10 independent variables used in the regression analysis could predict 54.66 per cent of the variation in the extent of technological gap in adoption of scientific practices of tea cultivation by the small tea growers.

The study concludes that there was substantial extent of technological gap in adoption of scientific practices of tea cultivation by the small tea growers .From study it was clear that massive capacity building programmes should be undertaken to develop knowledge and skills on scientific practices of tea 
cultivation of STGs and concerned agencies/ organizations should put more efforts in accelerating the adoption of scientific techniques of tea production.

Table.1 Distribution of respondents according to overall technological gap in adopting of scientific practices of tea cultivation

\begin{tabular}{|l|c|c|}
\hline $\begin{array}{l}\text { Technological gap category } \\
\text { (Score range) }\end{array}$ & Number & Percentage \\
\hline $\begin{array}{l}\text { Low overall technological gap } \\
\text { (0.00 to 37.75\%) }\end{array}$ & 17 & 17.00 \\
\hline $\begin{array}{l}\text { Medium overall technological gap } \\
\text { (37.76\% to 44.57\%) }\end{array}$ & 71 & 71.00 \\
\hline $\begin{array}{l}\text { High overall technological gap } \\
\left(\begin{array}{c|c|}\mathbf{4 4 . 5 7 \%} \text { to 100.00\%) } \\
\text { Total }\end{array}\right.\end{array}$ & 12 & 12.00 \\
\hline Mean & 100 & 100.00 \\
\hline S.D & 41.16 & \\
\hline C.V & 3.41 & \\
\hline
\end{tabular}

Table.2 Practice wise average technological gap in adopting of scientific practices of tea cultivation

\begin{tabular}{|c|l|c|}
\hline Sl. No. & Practices & $\begin{array}{c}\text { Average technological gap } \\
(\mathbf{\%})\end{array}$ \\
\hline $\mathbf{1 .}$ & Planting material & 13.90 \\
\hline $\mathbf{2 .}$ & Time of planting & 16.61 \\
\hline $\mathbf{3 .}$ & Spacing & 23.90 \\
\hline $\mathbf{4 .}$ & Time of vegetative propagation & 32.60 \\
\hline $\mathbf{5 .}$ & Number of ploughing and harrowing & 57.21 \\
\hline $\mathbf{6 .}$ & Size of main drain & 36.10 \\
\hline $\mathbf{7 .}$ & Size of planting pit & 61.71 \\
\hline $\mathbf{8 .}$ & Dose of chemical weedicide & 38.80 \\
\hline $\mathbf{9 .}$ & Length of pruning cycle & 48.90 \\
\hline $\mathbf{1 0 .}$ & Height of light prune & 49.70 \\
\hline $\mathbf{1 1 .}$ & Time of light prune & 41.41 \\
\hline $\mathbf{1 2 .}$ & Height of centering & 48.00 \\
\hline $\mathbf{1 3 .}$ & No of plucking round & 27.00 \\
\hline $\mathbf{1 4 .}$ & Chemical pest control & 48.40 \\
\hline $\mathbf{1 5}$ & Interval of irrigation & 43.41 \\
\hline $\mathbf{1 6 .}$ & Dose of YTD mixture & 70.90 \\
\hline $\mathbf{1 7 .}$ & Mulching Practices & 48.11 \\
\hline $\mathbf{1 8 .}$ & Dose of chemical pesticides & 37.81 \\
\hline $\mathbf{1 9}$ & Procedure of green leaf handling & 37.80 \\
\hline & Overall mean technological gap & 41.16 \\
\hline
\end{tabular}


Table.3 Correlation coefficient between extent of technological gap in adoption of scientific practices of tea cultivation and selected independent variables

\begin{tabular}{|c|l|c|c|}
\hline $\begin{array}{c}\text { Sl. } \\
\text { No. }\end{array}$ & \multicolumn{1}{|c|}{ Independent variables } & $\begin{array}{c}\text { Correlation } \\
\text { coefficient (r) }\end{array}$ & t-values \\
\hline $\mathbf{X}_{\mathbf{1}}$ & Age & -0.061 & 0.663 \\
\hline $\mathbf{X}_{\mathbf{2}}$ & Education & -0.122 & 1.256 \\
\hline $\mathbf{X}_{\mathbf{3}}$ & Family type & $-0.213^{*}$ & 2.157 \\
\hline $\mathbf{X}_{\mathbf{4}}$ & Family size & -0.171 & 1.758 \\
\hline $\mathbf{X}_{\mathbf{5}}$ & Area under tea & $-0.287^{* *}$ & 2.965 \\
\hline $\mathbf{X}_{\mathbf{6}}$ & Experience as a tea grower & -0.087 & 0.335 \\
\hline $\mathbf{X}_{\mathbf{7}}$ & Information source utilization & -0.049 & 0.409 \\
\hline $\mathbf{X}_{\mathbf{8}}$ & Institutional linkage & -0.105 & 1.049 \\
\hline $\mathbf{X}_{\mathbf{9}}$ & Occupational status & -0.122 & 1.215 \\
\hline $\mathbf{X}_{\mathbf{1 0}}$ & Economic motivation & $-0.223^{* *}$ & 2.263 \\
\hline $\mathbf{X}_{\mathbf{1 1}}$ & Management orientation & $-0.500^{* *}$ & 5.732 \\
\hline $\mathbf{X}_{\mathbf{1 2}}$ & Risk bearing ability & $-0.375^{* *}$ & 4.000 \\
\hline $\mathbf{X}_{\mathbf{1 3}}$ & Decision making ability & $-0.533^{* *}$ & 6.236 \\
\hline $\mathbf{X}_{\mathbf{1 4}}$ & Scientific orientation & $-0.476^{* *}$ & 5.351 \\
\hline $\mathbf{X}_{\mathbf{1 5}}$ & Exposure to training & $-0.394^{* *}$ & 4.243 \\
\hline $\mathbf{X}_{\mathbf{1 6}}$ & Net farm income & -0.037 & 0.601 \\
\hline $\mathbf{X}_{\mathbf{1 7}}$ & Working capital availability & $-0.202^{* *}$ & 2.041 \\
\hline $\mathbf{X}_{\mathbf{1 8}}$ & Farm mechanization & -0.093 & 0.332 \\
\hline $\mathbf{X}_{\mathbf{1 9}}$ & Knowledge level on scientific tea cultivation practices & $-0.409^{* *}$ & 4.438 \\
\hline
\end{tabular}

${ }^{* *}$ Significant at 0.01 level of probability

*Significance at 0.05 level of probability

Degrees of freedom $=(\mathrm{N}-2)$ for all cases

Table.4 Relative contribution of selected independent variable towards extent of technological gap in adoption of scientific practices of tea cultivation

\begin{tabular}{|c|l|c|c|c|c|}
\hline $\begin{array}{c}\text { SI. } \\
\text { No. }\end{array}$ & \multicolumn{1}{|c|}{ Independent variables } & $\begin{array}{c}\text { Regression } \\
\text { coefficient }\end{array}$ & $\begin{array}{c}\text { Standard } \\
\text { error of } \mathbf{b}_{\mathbf{i}}\end{array}$ & $\mathbf{t}$-value & $\mathbf{R}^{\mathbf{2}}$ \\
\hline $\mathbf{X}_{\mathbf{3}}$ & Family type & -1.112 & 0.602 & 1.845 & \\
\hline $\mathbf{X}_{\mathbf{5}}$ & Area under tea & -0.221 & 0.411 & 0.539 & \\
\hline $\mathbf{X}_{\mathbf{1 0}}$ & Economic motivation & $-0.213^{* *}$ & 0.085 & 2.492 & \\
\hline $\mathbf{X}_{\mathbf{1 1}}$ & Management orientation & -0.036 & 0.022 & 1.609 & \\
\hline $\mathbf{X}_{\mathbf{1 2}}$ & Risk bearing ability & -0.068 & 0.046 & 1.477 & \\
\hline $\mathbf{X}_{\mathbf{1 3}}$ & Decision making ability & $-0.164^{*}$ & 0.051 & 3.177 & 0.5466 \\
\hline $\mathbf{X}_{\mathbf{1 4}}$ & Scientific orientation & -0.122 & 0.075 & 1.622 & \\
\hline $\mathbf{X}_{\mathbf{1 5}}$ & Exposure to training & $-0.942^{* *}$ & 0.438 & 2.150 & \\
\hline $\mathbf{X}_{\mathbf{1 7}}$ & Working capital availability & -0.000122 & 0.00000221 & 0.549 & \\
\hline $\mathbf{X}_{\mathbf{1 9}}$ & Knowledge level on scientific practices of tea cultivation & $-0.161^{* *}$ & 0.073 & 2.190 & \\
\hline
\end{tabular}

*Significant at 0.05 level of probability

**Significant at 0.01 level of probability

Degree of freedom $=(\mathrm{N}-\mathrm{K})$ for all cases 
The findings of correlation analysis revealed that variables viz. area under tea, management orientation, risk bearing ability, decision making ability, scientific orientation, exposure to training, knowledge level on scientific practices of tea cultivation, family type, economic motivation and working capital availability for tea cultivation had negative and significant relationship with extent of technological gap. So, there is a need for extension agencies and other concerned departments to positively manipulate these crucial factors in order to bridge the technological gap in adoption of scientific practices of tea cultivation by the small tea growers.

\section{References}

Ahir, U.S. (1985). A study of the categories of the adopters of the rice varieties released by the Konkan Krishi Vidyapeeth. Unpublished M.Sc. Thesis, Dr. Balasaheb Sawant Konkan Krishi Vidyapeeth, College of Agric., Dapoli.

Ali, S. (2011). A study on performance of small tea growers self help group in Assam. Unpublished M.sc thesis submitted to Assam Agriculture University, Jorhat.

Anonymous (2007). An overview of the Tea industry in the north-eastern region and initiatives of the Tea Board. Tea Board of India.

Arya, N. (2014). India tea scenario. International journal of scientific and research publication, vol-3(7), PP-6-8

Bora, D.K. (1990). A study on extent of adoption of selected recommended package of practices of wheat crop by the farmers of Kaliabor Development Block of Nagaon district of Assam. Unpublished M.Sc. Thesis, Assam Agricultural University, Jorhat.

Chandrashekara, P. (1999). Knowledge and adoption gaps in coffee cultivation practices among coffee growers. Unpublished M.Sc. (Agri) Thesis, university of Agricultural Science, Bangalore.

Chutia, K. (1992). A study of differential adoption of recommended vegetables cultivation practices by summer and winter vegetables growers at different levels of commercialization in Jorhat District of Assam, Unpublished M.Sc Thesis, Assam Agricultural University, Jorhat.

Das, P.K. (1991). A Study of the Attributes of Technology and other Correlates of Adoption Behaviors of Beneficiary Farmers of Lab to Land Programme in Assam. Unpublished M.Sc. Thesis, Assam Agricultural University, Jorhat

Das, R.N. (2014). A study on the role of tea board of India in promotion of small tea growers with special reference to Dibrugarh district of Assam. Global Journal for Research Analysis, vol-3, 20-22.

Gogoi, P. (2013). A study on the extent of Adoption of recommended tea cultivation practices among the small tea growers of Golaghat district of Assam. Unpublished M.Sc. Thesis, Assam Agricultural University, Jorhat.

Gohain, J. (2006). Adoption of organic farming practices in vegetables crops in Upper Brahamputra Valley Zone (UBVZ) of Assam. Unpublished M.Sc. Thesis, Assam Agricultural University, Jorhat.

Goowalla, H. (2015). A study on the problems and prospect of small tea growers in Assam with special reference to Jorhat district, International Journal of Scientific Engineering and Applied Science, vol-1, pp-252-257.

Kalavathy, S. and Anithakumari, P. (1988). Extension of technology adoption in cowpea cultivation. Journal of Tropical 
Agriculture. 36(4): 1-2.

Kunzru, O.N., Sagar, R.L., Mandape, M.K., Kanbid, B.R and Singh, P. (1989). Adoption of green fodder production as related to some characteristics of livestock owners. Journal . of Extension Education. 25 (1 \&2): 85-88.

Mudoi, D and Dutta, S. (2016). Potential factors behind the rapid growth of small tea growers (STGs) in Golaghat district of Assam- An analysis. International Journal of Business and Administration Research Review, Vol. 2(1), 98-102.

Pathok, S. and Sasmal, B.C. (1992). Adoption of jute technologies. Indian Research.
Journal of Extension. Education, 28: 76-80.

Shukla, S.R. (1980). Adoption behavior of small farmers. Indian Research. Journal of Extension. Education, XVI: 55-58

Tharkar, D.M. and Patel, K.F. (1991). Factors affecting the adoption of summer groundnut technology, Gujarat Agricultural. University. Research. Journal. 17(1): 70-75.

Vennila, M.A. and Annamalai, R. (2000). Adoption behavior of millets growers in India. Indian Res. J. of Extn. Edn. 10 (3):75-83.

\section{How to cite this article:}

Parasar, S., P. K. Das, I. Barman, S. Sultana, S. Barman, S.D. Deka, N. Baruah and Islam, R. 2020. Factors Influencing the Extent of Technological Gap in Adoption of Scientific Practices of Tea Cultivation by Small Tea Growers of Assam. Int.J.Curr.Microbiol.App.Sci. 9(07): 17821789. doi: https://doi.org/10.20546/ijcmas.2020.907.204 